\title{
Effects of phonophoresis with acetic acid in the treatment of calcific tendinitis of the shoulder: case report
}

\author{
Edilene Araújo Pamplona', Andressa Medeiros Araújo', Heleodório Honorato dos Santos²,3
}

\begin{abstract}
Background: The calcific tendinitis of the shoulder is a dysfunction conservatively treated by shock waves, iontophoresis, and phonophoresis, associated or not with the use of acetic acid. Objective: To check the effects of phonophoresis with acetic acid in the treatment of calcific tendinitis of the shoulder in resorption stage. Methods: Measurements of ROM, muscle strength and functionality of the shoulder (SPADI) were made pre and post-physiotherapeutic treatment. The treatment protocol consisted of 10 sessions of therapeutic ultrasound with acetic acid (frequency $=3 \mathrm{MHz}$; intensity $=1.4 \mathrm{~W} / \mathrm{cm} 2$; pulsed mode of 1:4), for 10 minutes, 3 times a week. The data were analyzed using the SPSS software (20.0), through the Student's t-test (paired) considering a significance level of $5 \%$. Results: There was significant improvement regarding the ROM, muscle strength and functionality of the right shoulder (SPADI) comparing pre vs. post-treatment $(P<0.01)$. In addition, there were no statistically significant differences $(P>0.05)$, in the comparison between the shoulders (right X left) in the post-treatment. Conclusion: According to the results of this case study, the protocol used (10 sessions of therapeutic ultrasound $+5 \%$ acetic acid) was effective in the treatment of calcific tendinitis of shoulder, improving the ROM, muscle strength and functional capacity, in addition to eliminating the pain of the shoulder affected.
\end{abstract}

Key-words: Shoulder Pain, Calcinosis, Physiotherapy, Acid-base Imbalance.

\section{INTRODUCTION}

The calcific tendinitis is a disorder that occurs most commonly in people aged between 30 and 60 years, presenting higher incidence in female gender ${ }^{(1)}$. It is characterized by the deposition of hydroxyapatite crystals that principally affects the tendons of the rotator cuff( ${ }^{(2)}$, and the tendon of the supraspinatus often the most affected ${ }^{(3)}$. Its etiology is controversial and it has been suggested that a local hypo vascularization of Codman in the tendon of the supraspinatus is responsible for initiating the degenerative process, which subsequently leads to calcification ${ }^{(4)}$. Regarding its symptoms, it can be found in asymptomatic individuals, where calcification is a mere radiological finding ${ }^{(2)}$, or symptomatic, in which the pain and loss of range of motion (ROM) are the most reported complaints ${ }^{(5)}$.

The calcific tendinitis is a self-limiting disease which corresponds to $17 \%$ of the syndromes of the shoulder ${ }^{(6)}$, and can be divided into three stages: pre-Calcification (where there is a metaplasia of the tendon tissue in fibrocartilage); calcification which is divided into resting phase and of reabsorption (the latter is the phase where there is intense pain and functional limitation, in which the calcium deposition looks like tooth paste) and; Post-calcification where there is spontaneous resorption of calcification and pain regression ${ }^{(7)}$. Despite of the surgical removal of calcification or percutaneous needle aspiration can be used, even if in the last case, conservative treatment is the most indicated in calcific tendinitis, which can be carried out with the use of: analgesics, non-steroid anti-inflammatory, infiltration of corticosteroids ${ }^{(8)}$, extracorporeal shock waves therapy and physiotherapy ${ }^{(9)}$.

In the case of the physiotherapeutic treatment for calcific tendinitis, the use of acetic acid has been the substance used with greater frequency in not only the phonophoresis - introduction of substances through therapeutic ultrasound ${ }^{(10)}$, although there are few studies, but also the iontophoresis - introduction of substances through Galvanic current ${ }^{(11-13)}$, due to the fact that it promotes a chemical reaction capable of forming a compound more soluble which facilitates the calcium absorption ${ }^{(13)}$. Therefore, the objective of this study was to verify the effects of

Correspondence: Heleodório Honorato dos Santos. Av. Monsenhor Odilon Coutinho, 191, apto. 402 - Cabo Branco; João Pessoa, PB, Brazil. CEP: 58045-120 Tel: 005583 3216-7183; 005583 99613-7900. E-mail: dorioufpb@gmail.com

2 PhD. Professor from the Physiotherapy Department - Universidade Federal da Paraíba (UFPB), João Pessoa, PB, Brazil.

${ }^{3}$ Professor of Associate Program of Graduation Studies in Physical Education (PAPGEF) - UPE/UFPB, João Pessoa, Paraíba, Brazil.

Full list of author information is available at the end of the article.

Financial Support: nothing to declare

Submission date 10 August 2017; Acceptance date 23 November 2017; Publication date 08 December 2017 
phonophoresis with acetic acid in the treatment of a patient with calcific tendinitis of the shoulder in reabsorption stage.

\section{METHODS}

\section{Type of study}

The work herein is featured by a case report of a patient with pain and limitation of movement in the articulation of the right shoulder, having been diagnosed by an orthopedic doctor, with calcific tendinitis of the muscle supraspinatus, and confirmed by imaging examination (X-ray).

\section{Sample characteristics}

Publicist, female, 34 years old, sought the service of the Physical Therapy Clinic School from the Federal University of Paraíba (PTCS/UFPB) for physiotherapeutic treatment, complaining of pain and decreased mobility of the right shoulder.

\section{Procedures}

Initially, the patient underwent a functional kinetic evaluation which consisted of: measures of range of motion (ROM) with the Universal Goniometer (UG - CARCI, São Paulo - SP, Brazil); tests of muscular strength to the movements of both shoulders (flexion, hyperextension, abduction, medial rotation, lateral rotation, adduction and horizontal abduction) and application of the Brazilian version of Shoulder Pain and Disability Index (SPADI) with the aim of assessing pain and disability associated with dysfunction of the shoulder. It was requested a radiography prior to the beginning of the physiotherapeutic treatment (Figure 1A) to verify the presence of calcification and its location and, subsequently, another radiograph after the end of the sessions (Figure 1B).

\section{Goniometry}

For checking the ROM of shoulder, pre and post-intervention of the following movement were measured:

- Flexion - Subject kept in a supine position; pivot located on the lateral axis of the shoulder, a line below the acromion; fixed arm parallel to the mid-axillary line and; movable arm on the lateral surface of the arm, in its mid-line;

- Medial and lateral rotation - subject in lateral decubitus position with the shoulder in abduction 90\%; elbow flexed at $90^{\circ}$ and, forearm in neutral position. Fixed arm perpendicular to the ground and movable arm facing dorsal surface of the forearm, along the middle line which goes from the olecranon until the process of the ulna;

- Adduction and horizontal abduction - individual in the supine position with the shoulder abducted to $90^{\circ}$; pivot located on the acromion, fixed arm parallel to the sagittal axis and movable arm on the lateral surface of the arm, parallel to the longitudinal axis of the humerus;

- Hyperextension - the individual was maintained in ventral decubitus and the same parameters described for the flexion were used;

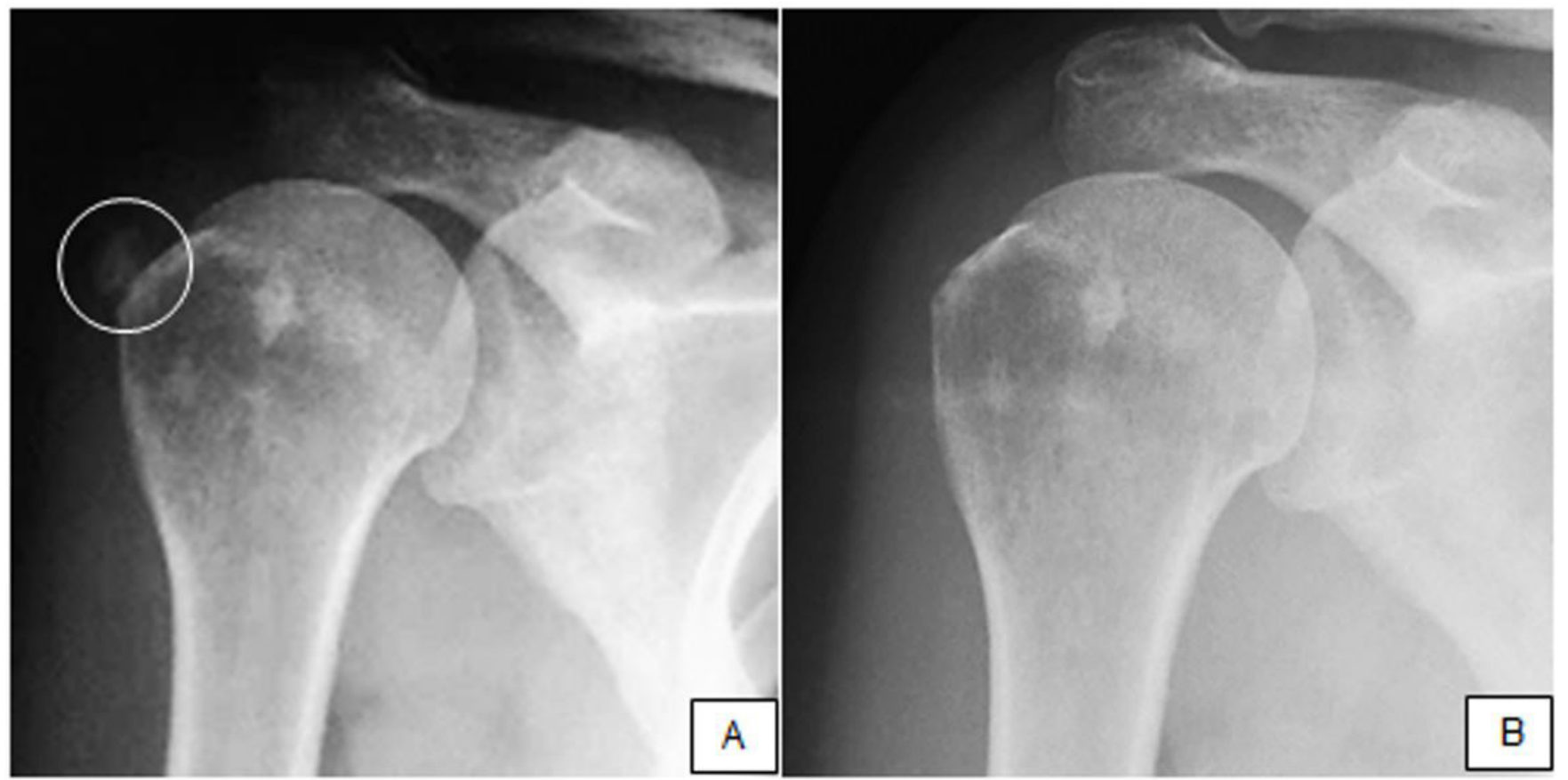

Figure 1. Right shoulder X-ray, anteroposterior view, pre (A - toothpaste aspect) and posttreatment (B) 
- Abduction - the individual was maintained standing up; pivot located on the anterior surface of the shoulder, below the line of the acromion (center of the head of the humerus); fixed arm parallel to the sternum and movable arm along the anterior surface of the arm.

\section{Tests of muscle strength}

To evaluate the muscle strength, the dynamometer digital Muscle Tester - MMT was used (Lafayette Instrument, Indiana - USA). The measurements were performed with the individual in the sitting and dorsal decubitus position, being quantified the muscular strength for flexors, extensors, adductor and medial rotators and laterals of both shoulders. For each movement three measurements (in Newtons) were obtained and calculated the average for statistical effect.

\section{Pain and shoulder dysfunction}

The pain and disability associated with the shoulder dysfunction were evaluated by the Brazilian version of Shoulder Pain and Disability Index - SPADI I4) which is a questionnaire on life quality composed of 13 items distributed in the field of pain (5 items) and function ( 8 items), in which each item is scored on a numerical scale from 0 to 10 points, which can reach a total score of 130 points, where the highest score equates to the worst worse condition of shoulder dysfunction.

\section{Intervention Protocol}

For the physiotherapeutic treatment the patient remained in the lateral decubitus with the right shoulder (affected) facing up. Ten sessions were held ( $3 \mathrm{x}$ week), with a therapeutic ultrasound (Sonopulse III - Ibramed, Amparo - SP, Brazil), calibrated on the calcification area (insertion of the supraspinatus muscle) with the following parameters: 1 - frequency of $3 \mathrm{MHz} ; 2$ - intensity $1.4 \mathrm{~W} / \mathrm{cm} 2$; 3 - application method: pulsing (1:4); 4 - effective issue area (EIA) of the head of $7 \mathrm{~cm}^{2} ; 5$ - Time of application: 10 minutes and $6-5 \%$ acetic acid, in the form of gel, was used as couplant.

The individual participating of the study was informed about the research and signed an Informed Consent Form (ICF), agreeing to participate in this study, which was approved by the Research Ethics Committee from the Health Sciences Center of Federal University of Paraíba (CEP/CCS/UFPB), according to protocol number 204.285 and CAAE: 12500313.5.0000.5188.

\section{Data Analysis}

The statistical procedures (descriptive and inferential) were made in the electronic spreadsheet Statistical Package for the Social Sciences (SPSS - 20.0). Initially, the data normality was observed (Shapiro Wilk's test) and then used the " $\mathrm{t}$ " test (paired) to compare the ROM, muscle strength and the level of disability and shoulder pain (SPADI), pre versus post-intervention; and the " $\mathrm{t}$ " test (independent) to compare these variables between the sides (right versus left), taking into account a significance level of $\mathrm{P} \leq 0.05$ in all analyzes.

\section{RESULTS}

At the measurements of ROMs of shoulder, pre vs. post-treatment, the Student's t-test (paired), showed a statistically significant difference for the right side ( $P=0.003)$, however, for the left side this difference was not found $(P=0.689)$.

As for the comparisons of ROMs of shoulder, between sides (right X left), it can be observed, in the pre -physiotherapeutic treatment (Table 1), a statistically significant difference $(P=0.001)$, showing that the right side (affected) showed drastic reduction in ROMs of shoulder, while the post-treatment evaluation, there was no statistical difference $(P=0.996)$ between the measurements.

Regarding the shoulder muscle strength, pre vs. post-treatment, the Student's t-test (paired), showed a statistically significant difference for the right side $(P=0.001)$, however, for the left side this difference was not found $(P=0.186)$. Regarding the comparison between sides (right $X$ left), there was also a statistically significant difference $(P=0.001)$, in the pre -treatment evaluation, showing a deficit of strength on the right side (Table 2), however, at

Table 1. Comparison of shoulder ROM (degrees) between right and left sides pre- and post-treatment physiotherapeutic

\begin{tabular}{|c|c|c|c|c|c|c|}
\hline \multirow{2}{*}{ Motions } & \multicolumn{3}{|c|}{ Pre-treatment } & \multicolumn{3}{|c|}{ Post-treatment } \\
\hline & Right & Left & P Valor & Right & Left & P Valor \\
\hline Flexion & 20 & 165 & & 178 & 164 & \\
\hline Hyperextension & 17 & 40 & & 30 & 40 & \\
\hline Abduction & 30 & 180 & & 176 & 180 & \\
\hline Lateral Rotation & 0 & 90 & 0.001 & 95 & 90 & 0.996 \\
\hline Medial Rotation & 0 & 92 & & 85 & 94 & \\
\hline Horizontal Abduction & 0 & 56 & & 56 & 56 & \\
\hline Horizontal Adduction & 0 & 136 & & 144 & 136 & \\
\hline
\end{tabular}

Note: $\mathrm{ROM}=$ range of motion; $\mathrm{t}$ Student test (nonpaired)

Table 2. Comparison of shoulder muscle strength $(\mathrm{N})$ between right and left sides, pre- and post-treatment physiotherapeutic

\begin{tabular}{|c|c|c|c|c|c|c|}
\hline \multirow{2}{*}{ Motions } & \multicolumn{3}{|c|}{ Pre-treatment } & \multicolumn{3}{|c|}{ Post-treatment } \\
\hline & Right & Left & P Valor & Right & Left & P Valor \\
\hline Flexion & 17.2 & 39.1 & & 42.9 & 38.0 & \\
\hline Hyperextension & 20.8 & 40.3 & & 34.7 & 38.1 & \\
\hline Abduction & 26.8 & 36.5 & & 44.7 & 45.6 & \\
\hline Lateral Rotation & 18.8 & 39.9 & 0.001 & 46.9 & 40.6 & 0.186 \\
\hline Medial Rotation & 20.8 & 47.4 & & 51.8 & 59.2 & \\
\hline Horizontal Abduction & 30.8 & 59.3 & & 51.4 & 60.5 & \\
\hline Horizontal Adduction & 27.1 & 45.0 & & 45.2 & 46.5 & \\
\hline
\end{tabular}

Note: $\mathrm{N}=$ Newton; $\mathrm{t}$ Student test (nonpaired) 
the post-treatment evaluation, there were no statistically significant differences $(P=0.186)$ between the measures.

Concerning the level of disability and pain in the right shoulder, measured by the Shoulder Pain and Disability Index (SPADI), in the pre -treatment the individual achieved an overall score of 117 , for a maximum of 130 points, reducing to zero (0) point in the post treatment evaluation, thus showing, a significant difference $(P<0.001)$ between the evaluations. The improvement in the patient's clinical condition, that is: gain of the ROM; muscular strength; the functionality; and lack of shoulder pain; can be corroborated in the post-treatment radiographic (Figure 1B)

\section{DISCUSSION}

The reason for the calcium deposition in the rotator cuff is still not well understood, but factors such as: 1) relative ischemia as a result of hypo vascularization in the so-called critical zone of the rotator cuff; 2 ) degeneration of the tendons and; 3 ) metabolic disorders, have been suggested as possible causes $^{(6)}$.

In this study, an improvement in the ROM was identified in the shoulder joint, in all movements assessed, as an effect of the therapeutic intervention proposed. These results corroborate the study of Henriques and Henriques ${ }^{(13)}$ that, although has used the iontophoresis (Galvanic current) as a means of introducing the $5 \%$ acetic acid, also found an improvement in the shoulder ROM in a patient submitted to 15 sessions of treatment. In the final phase of the treatment, a significant increase was also observed in the strength of the muscles of the right shoulder when the sides were compared (right $X$ left). This effect is a consequence of the decline of the process of tendon calcification of supraspinatus tendon and the local inflammatory reaction which, according to Gosling and Laucas ${ }^{(15)}$, is related to the muscular strength. In the individual under, the following was identified: improved function and decreased pain in the shoulder joint, observed by means of the questionnaire Shoulder Pain and Disability Index (SPADI) after application of the phonophoresis with acetic acid, indicating that the disability and pain, before diagnosed, were no longer present.

These results corroborate the studies of Ebenbichler et al. ${ }^{(2)}$, Perron and Malouin ${ }^{(5)}$ and Toro et al. ${ }^{(11)}$ that, despite of having used different methodologies (only therapeutic ultrasound; and ontophoresis with $5 \%$ acetic acid + therapeutic ultrasound, respectively) reported the efficacy of treatment through the decreased almost total level of pain in subjects with calcareous tendinitis of the shoulder.

In the phonophoresis process, the effects of ultrasonic energy open paths that allow the medication to be spread over the skin and penetrate more deeply into the tissues ${ }^{(16)}$. The application of ultrasound, causing thermal effects, disorganizes the outermost layer of the skin, reducing its strength at $30 \%{ }^{(17)}$. Furthermore, the athermic effects originating from mechanical events (cavitation, chains and micro flux) produced by the passage of sound wave in the tissues and are related to increased skin and cell membrane permeability that allow the passage of drugs ${ }^{(6)}$. The justification for the use of acetic acid is based on a chemical reaction $\left(\mathrm{CaCO} 3+2 \mathrm{H}(\mathrm{C} 2 \mathrm{H} 3 \mathrm{O} 2) 2=\mathrm{Ca}(\mathrm{C} 2 \mathrm{H} 3 \mathrm{O} 2) 2+\mathrm{H} 2 \mathrm{O}+\mathrm{CO}_{2}\right)^{(12)}$ where the molecules of insoluble calcium carbonate combine with acetic acid to form calcium acetate, which is more soluble and therefore more easily dissolved within tendons and other soft tissues than the calcium carbonate ${ }^{(18)}$.

Added to this the fact that, ultrasound activates the endothelial cells which express and release a variety of substances, such as: chemokines (attractive protein of monocytes chemo, interleukin-8, regulated upon activation of normal T cells expressed and segregated [RANTES]) and cytokines (interleukin 2 and factor of stem cells), as well as macrophages migrants may be involved in the phagocytosis of calcified particles. The ultrasound applied in higher intensities can trigger or accelerate the breakdown of microcrystals of apatite into smaller crystals and stimulate macrophages to remove them by phagocytosis ${ }^{(7)}$. It should be noted that, as in any case report, the results of the study cannot be generalized and, therefore it would be advisable to continue this study with a larger sample of patients, since the physiotherapeutic approach was applied in only one individual.

\section{CONCLUSION}

According to the results of this case study, the protocol used ( 10 sessions of therapeutic ultrasound $+5 \%$ acetic acid) was effective in the treatment of calcific tendinitis of shoulder, improving the ROM, muscle strength and functional capacity, in addition to eliminating the pain of the shoulder affected.

\section{Acknowledgements}

To the director of the Physiotherapy Clinical School of the Federal University of Paraíba / UFPB, for the collaboration and support in this study.

\section{AUTHORS' CONTRIBUTION}

EAP: Data collection and preparation of the manuscript; AMA: Data collection and preparation of the manuscript; HHS: Statistical treatment; preparation and revision of the manuscript.

\section{CONFLICTS OF INTEREST}

Nothing to declare.

\section{AUTHOR DETAILS}

1 Physiotherapy course students from the Universidade Federal da Paraíba (UFPB), João Pessoa, PB, Brazil.

\section{REFERENCES}

1. Speed A, Hazleman L. Calcific tendinitis of the shoulder. N Engl J Med. 1999; $340(20): 1582-4$ 
2. Ebenbichler GD, Erdogmus $C B$, Resch $K L$, Funovics $M A$, Kainberger $F$, Barisani $G$, et al. Ultrasound therapy for calcific tendinitis of the shoulder. N Engl J Med. 1999; 340(20):1533-8.

3. Ejnismann B, Monteiro GC, Uyeda LF. Ombro doloroso. Einstein. 2008; 6(Supl 1):S133-S7.

4. De Palma AF. Calcareous tendinitis. In: DePalma AF. Surgery of the shoulder. 3rd ed. Philadelphia: Lippincott; 1983. p. 257-85.

5. Perron M, Malouin F. Acetic acid iontophoresis and ultrasound for the treatment of calcifying tendinitis of the shoulder: a randomized control trial. Arch Phys Med Rehabil. 1997; 78(4):379-84.

6. Santos JS, Marinho RBDM, Araújo AR, Chaves MEA, Nascimento MP, Pereira AM. O ultrassom é efetivo no tratamento da tendinite calcárea do ombro? Fisioter. Mov. 2012; 25(1):207-17.

7. Kachewar SG, Kulkarni DS. Calcific tendinitis of the rotator cuff. J Clin Diag Res. 2013; 7(7):1482-5.

8. Rompe JD, Zoellner J, Nafe B. Shock wave therapy versus conventional surgery in the treatment of calcifying tendinitis of the shoulder. Clin Orthop Relat Res. 2001; 387(1):72-82.

9. Wageck JPZ, Fernandez JS, Bender FL, Gervini FM. Tendinite calcárea do ombro. Acta Med (Porto Alegre). 2007; 28:270-9.

10. Khan J. Acetic acid iontophoresis for calcium deposits: suggestion from the field. Phys Ther. 1977; 57 (5):658-9.
11. Toro JR, Monje MR, Puentes EC, Rebollo AG, Sánchez EB. Tratamiento de la tendinitis calcificante del hombro mediante iontoforesis con ácido acético y ultrasonidos. Rehabil. (Madr). 2001; 35(3):166-70.

12. Leduc BE, Caya J, Tremblay S, Bureau NJ, Dumont M. Treatment of calcifying tendinitis of the shoulder by acetic acid iontophoresis: a double-blind randomized controlled trial. Arch Phys Med Rehabil. 2003; 84(10):1523-7.

13. Henriques $M$, Henriques R. Acetic acid iontophoresis in the treatment of calcifying tendinitis of the shoulder. Rev Soc Port Med Fís Reabil. 2014; 25(1):38-43.

14. Martins J, Napoles BV, Hoffman CB, Oliveira AS. versão brasileira do Shoulder Pain and Disability Index: tradução, adaptação cultural e confiabilidade. Ver Bras Fisioter. 2010; 14(6):527-36.

15. Gosling AA, Laucas BP. Abordagem fisioterapêutica da tendinite calcificante do músculo supra-espinhal: uma revisão da literatura [TCC de Fisioterapia]. Belo Horizonte (MG): Universidade Federal de Minas Gerais; 2009.

16. Jesus GS, Ferreira AS, Mendonça AC. Fonoforese x permeação cutânea. Fisioter Mov. 2006; 19(4):83-8.

17. Paliwal S, Mitragotri S. Ultrasound-induced cavitation: applications in drug and gene delivery. Expert Opin Drug Deliv, 2006; 3(6):713-26.

18. Wieder DL. Treatment of traumatic myositis ossificans with acetic acid iontophoresis. Phys Ther. 1992; 72(2):133-7. 